\title{
Communication in the void and communication avoided: a case study of on-line language teaching
}

Alex Boulton and Paul Booth

\section{OpenEdition}

\section{Journals}

\section{Electronic version}

URL: http://journals.openedition.org/asp/1877

DOI: $10.4000 /$ asp. 1877

ISBN: 978-2-8218-0384-8

ISSN: 2108-6354

\section{Publisher}

Groupe d'étude et de recherche en anglais de spécialité

\section{Printed version}

Date of publication: 1 October 2001

Number of pages: 89-102

ISSN: 1246-8185

\section{Electronic reference}

Alex Boulton and Paul Booth, "Communication in the void and communication avoided: a case study of on-line language teaching », ASp [Online], 31-33 | 2001, Online since 11 November 2010, connection on 21 April 2019. URL : http://journals.openedition.org/asp/1877; DOI : 10.4000/asp.1877

This text was automatically generated on 21 April 2019

Tous droits réservés 


\title{
Communication in the void and communication avoided: a case study of on-line language teaching
}

\author{
Alex Boulton and Paul Booth
}

\section{Introduction}

1 An eternal problem facing materials writers in all areas is making sure that instructions are completely transparent. Indeed, it seems obvious that the success rate in any test should depend on the difficulty of the task, not on understanding what is required. This is most commonly seen in: published materials, self-access materials, distance learning materials, Internet materials and autonomous study materials.

What these all have in common is that the materials writer is not on hand to provide immediate explanation as soon as the need arises. For the majority of language teachers in the past, such problems have only really appeared when preparing instructions for homework and exams; in most other situations, the teacher is physically present and so able to spot difficulties and to provide the necessary clarifications.

3 And yet electronic communications are making their presence felt throughout the entire field of education, so that even classroom teachers cannot afford to ignore them (Pincas 1998: 133). Indeed, more and more teachers are now putting materials on their university web site for autonomous work, effectively combining all of the areas outlined above. Welcome to e-learning, the seemingly oxymoronic world of on-site distance learning.

As more and more transactions are conducted through computer-mediated communication (CMC), the likelihood of a breakdown in communication inevitably increases. This is a particular source of concern in language teaching, which is justifiably proud of a long history of pedagogical research compared to most disciplines. Indeed, teachers on many training programmes are assessed as much on their teaching techniques and "human" skills as on their knowledge of the subject. The question then arises as to the similarity between classroom and Internet teaching and the ease of 
transition from one to the other. As we shall see in this paper, extreme positions of total separation or total overlap are equally unrealistic. On the one hand, many of the skills involved in Internet teaching can be carried over from classroom work, especially where the teacher has experience of materials writing, autonomous work, and so on; many of the questions encountered here will be familiar to teachers already. On the other hand, the separation of teacher and student for substantial portions of the course is a novel experience which should not be underestimated, and can lead to a number of problems. In particular, given the lack of feedback, the teacher may have the feeling of teaching into a void, the student of learning in a void.

5 The aim of this paper is not to present the advantages of using the Internet, e-mail and other such information technologies, as this has been done many times before (e.g., Dudeney 2000). Rather, we shall be looking at a number of potential dangers inherent in communicating at a distance, where students are unused to such practices. What kind of mediation is possible between learner and teacher in the Internet void? What kind of general communication problems occur most frequently? And how can they be avoided?

\section{Background}

6 In order to place the present study in context, we need to present the Centre de Téléenseignement Universitaire - Université Nancy 2 (CTU). Briefly, there are currently 5 teachers on full-time posts at the centre, accounting for $60 \%$ of core courses; 13 outside teachers from Nancy 2 and further afield are solicited mainly for optional courses. In the year concerned (2000-2001), there were a total of 869 students enrolled for specialist and non-specialist English courses, from first year through to a maitrise in the fourth year. The CTU has been in existence since the 1960s, providing a wealth of experience in traditional materials writing. Furthermore, individual courses have been available on Internet for some years now, and the entire programme is available on-line as of September 2001.

7 The main source of data for this paper is a student questionnaire, allowing a largely statistical analysis of student representations; the results are highly abbreviated here. As we were mainly interested in student-teacher interaction through Internet and e-mail under the broad heading of CMC - we decided to send the questionnaire by e-mail. This provided a means of limiting our study to those students who were interested enough in such technology to have a working address. Furthermore, only e-mail responses were accepted, thus restricting our final sample to students who were sufficiently competent in the use of such technology that they could open, complete and return the questionnaire successfully.

8 Just over a third of students enrolled are known to have an e-mail address. The questionnaire was sent to all of these students; exactly one third returned the document successfully, providing a final population sample of 63 - 31 enrolled in the DEUG (first two years), 32 in the licence (third year). Again, it is to be expected that this sample is not representative of our student population as a whole, but it should be stressed that we were particularly interested in students who were sufficiently interested and competent in the use of the necessary technology to a) have an e-mail address, b) manage to open the document, c) manage to complete it, and d) return it successfully. 
The questionnaire itself was in French, focusing on two main areas: a) contact between the students and the teachers; $b$ ) the course itself, and written homework assignments in particular. Most of the questions were closed-style multiple choice, but subjects were encouraged to add other comments throughout in spaces provided.

10 Additional data sources comprised a series of informal interviews conducted with all the full-time teachers, and analysis of students' homework. We look first at communication problems in general, then at problematic instructions.

\section{Contact in the void}

11 The first major problem of communication breakdown seems to be based on a simple lack of contact. During the interviews, teachers frequently expressed frustration at not knowing who the students actually are, a problem also cited by Dubin and Olshtain (1986). Communication really does happen in a void: "this communication medium... appears to disguise a person's appearance and cultural identity" (Ryan 1992). This is compounded by the fact that when writing any type of materials, it is helpful to have an audience in mind. There is also a feeling of inequality. Teachers put their ideas, comments and opinions into the materials, and yet they feel that the communication is not reciprocal.

Given the difficulties of teaching and learning in this void, the CTU allows for formal and informal contact between teachers and students; indeed, the need for support back-up has been extensively covered (e.g. Simpson 2000). At the CTU, the formal type of contact consists of organised regroupements, in which students come to the university on a certain day to meet their peers and their teacher. These meetings are also appreciated by teachers, as they draw their attention to problems they had not envisaged.

It is only natural that the CTU should provide support outside these formal meetings, where teachers are available to answer students' questions (cf. Esch 1994). To this end, students are constantly encouraged to contact their teachers and each other via a number of different media. Not surprisingly for our population sample, the majority of contact was via e-mail. For distance students, many of whom live far from the university, this is no doubt more practical than a face-to-face meeting, cheaper than the telephone, and easier and more flexible than normal post or fax. The advent of e-mail has helped to overcome some of the problems of geography in distance learning, as Makin (1994) has pointed out. One teacher expressed the view that, prior to e-mail, there was not really a relationship at all between himself and his students. Today, teachers regard e-mail as an important tool to understand students' difficulties, especially at a distance. Indeed, more and more of the students' work arrives at the CTU via e-mail. These e-mails can be answered quickly and are perhaps less threatening for students than a direct telephone call.

Unfortunately, despite repeated offers in the student's guide and in the courses, few students make sufficient use of teachers' availability (see Table1). Teachers, however, feel that the onus is on the students to contact them rather than vice versa. The course itself is seen as providing the means of pre-empting as many general questions and difficulties as possible, but it is not feasible to predict every potential problem, nor is it realistic to address everything in the course. For this reason, individual contact tailored to specific difficulties has to be student-initiated. 

together with the previous question, less than half of our initial sample have had more than a single contact experience with their teachers, while only two out of the 63 respondents claim regular contact.

Table 1. How often have you contacted your teachers?

\begin{tabular}{|l|l|l|l|l|}
\hline & often & occasionally & once & (never) \\
\hline DEUG & 1 & 13 & 6 & $(11)$ \\
\hline Licence & 1 & 16 & 10 & $(5)$ \\
\hline Total & 2 & 29 & 16 & $(16)$ \\
\hline
\end{tabular}

Anticipating low results, we further questioned these students about their motivations for not getting in touch (see Table 2). For nearly a third of the respondents it was a question of time - many students have children or a full-time job or both, and consequently experience difficulty in organising their time ${ }^{1}$. Worse still is that 5 of the 16 DEUG students who answered this question are apparently afraid of asking silly questions, a number of students providing additional answers such as " $\mathrm{J}$ 'ai peur d'embêter les professeurs," or "Je n'ose pas trop appeler car j'ai peur de déranger."

This is no doubt partly because the teachers remain virtuels, in the words of one student. Fortunately, only one third-year student gave this answer. More encouraging is that $28 \%$ claim they simply have no questions to ask: "Les cours sont très bien expliqués et j'essaye de me débrouiller par moi-même."

19 The teachers interviewed are quite aware of this "fear factor", but add that there may be something of a vicious circle here. The weakest or least brave students do not even dare to submit their homework, and without this initial correction they are then even less willing to contact the teachers. Hence it is precisely those who have the greatest need of contact that feel they cannot because of lack of face.

Table 2. Why have you not contacted your teachers?

\begin{tabular}{|l|l|l|l||l|l|}
\hline & no time & no question & fear & other & total \\
\hline DEUG & 4 & 4 & 5 & 3 & 16 \\
\hline Licence & 3 & 3 & 1 & 2 & 9 \\
\hline total & 7 & 7 & 6 & 5 & 25 \\
\hline
\end{tabular}


Such contact as there is focuses largely on essentials. Nearly half of all cases concerned homework and exam requirements, a further third matters of administration and resources; only $14 \%$ of contact was taken up with discussing questions of course content. This concords with Thorpe's findings (1988: 74) that student perceptions of the help they need from teachers in distance courses focus very largely on explanation of homework assignments.

In summary, despite repeated exhortations for the students to get in touch, it seems that, in most cases, this only happens when it is virtually inescapable. They initiate contact only when they have a concrete problem to sort out, and even then they are as likely as not to let it go rather than appear foolish. And yet students do experience problems. The implication is that it is essential for teachers to ensure that information provided is as clear and explicit as possible, since negative feedback cannot be relied upon to ascertain areas of difficulty.

\section{Instructions in the void}

We turn now from communication as a whole to more specific problems arising through instructions in homework. Indeed, over half of the students questioned admitted a degree of difficulty in understanding what was required (see Table 3).

Table 3. Do you ever experience difficulty understanding what is required?

\begin{tabular}{|l|l|l|l|l|}
\hline & often & sometimes & never & total \\
\hline \hline DEUG & 3 & 14 & 14 & 31 \\
\hline Licence & 4 & 12 & 15 & 31 \\
\hline total & 7 & 26 & 29 & 62 \\
\hline
\end{tabular}

This point seemed to us to be sufficiently important to warrant a more explicit back-up question (see Table 4). This time, we asked students if they had ever lost points in their homework because they had not understood the questions. While nearly two thirds of students still claim this has happened to them at some time in the past, only one student admitted it was a frequent problem. In the words of one subject: "Je pense comprendre ce que veut l'enseignant et à la correction je vois que ce n'était pas ça."

Table 4.Have you ever lost points because you did not understand the instructions?

\begin{tabular}{|l|l|l|l|l|}
\hline & often & sometimes & never & total \\
\hline DEUG & 0 & 18 & 11 & 29 \\
\hline Licence & 1 & 17 & 11 & 29 \\
\hline \hline total & 1 & 35 & 22 & 58 \\
\hline
\end{tabular}



submitting papers with inappropriate format, including insufficient margins, or omitting their names and other essential information from their papers, especially on e-mail attachments. Numerous careless errors were found, along with poor strategies, including copying out the questions, failing to use language given elsewhere in the paper, and not basing answers on examples provided. More specifically, however carefully the questions are phrased, it seems that there is always room for misunderstanding. Two brief examples should suffice using the simplest question formats, as experienced teachers will no doubt be familiar with the types of problem encountered:

Cloze: Although the instructions required a single preposition for each gap, a number of students provided two-word answers, and several gave optional answers. Not all answers were prepositions, and some items were left unanswered altogether.

Grid completion: This question required students to complete a grid of irregular verbs. Surprisingly, many blanks remained here, although any dictionary or grammar book would supply the answers. Furthermore, where the question goes against student expectations, they tend to assume that it is the teacher who is wrong rather than themselves. For example, given the past participle founded, some students rewrote the question to provide the answer find/found/found.

It should be stressed that this is only the briefest summary of the simplest question types. As an after-word, it is encouraging to note that the majority of students (see Table 5) have a preference for questions requiring longer answers in English rather than the simplest multiple-choice (barely one in four) or gap-fill style questions.

Table 5. What type of homework questions do you prefer?

\begin{tabular}{|l|l|l|l|l|l|}
\hline & $\begin{array}{l}\text { multi-choice, true/ } \\
\text { false, yes/no... }\end{array}$ & $\begin{array}{l}\text { one-word } \\
\text { answers, } \\
\text { gap-fill... }\end{array}$ & $\begin{array}{l}\text { discussion, comparison, } \\
\text { analysis... }\end{array}$ & $\begin{array}{l}\text { essay } \\
\text { questions }\end{array}$ & total \\
\hline DEUG & 9 & 7 & 13 & 1 & 30 \\
\hline Licence & 6 & 4 & 17 & 1 & 28 \\
\hline total & 15 & 11 & 30 & 2 & 58 \\
\hline
\end{tabular}




\section{Language and culture}

One of the first choices to be made in designing written materials is the language to be used. It may seem obvious that instructions, for the sake of clarity, should be written in the students' mother tongue (L1). However, the majority of courses at the CTU are in English, and there do seem to be a number of good reasons for this. One primary reason is simply pragmatic: it is easier for the native materials writer, and provides protection against subsequent claims for redress where misunderstanding does occur. Secondly, in the case of the CTU, not all students are native French speakers, but all have the study of English in common, so this may be considered a "fairer" medium. Thirdly, instructions in the target language can be used to provide valuable clues and language which students can use in their answers. Fourthly, constant switching back and forth between L1 and the target language (L2) may impede communication, both linguistically and culturally.

Furthermore, it is interesting to see that none of the students surveyed considered the language to be a major barrier (see Table 6). While a small minority of DEUG students admit that English as a medium does pose occasional problems, over $90 \%$ of respondents overall consider courses in the target language to be a "plus" in their education. Furthermore, many of the students use English in their contact with teachers, and even with each other.

Table 6. How do you feel about courses in English?

\begin{tabular}{|l|l|l|l|l|}
\hline & a major barrier & a minor barrier & a "plus" in the course & total \\
\hline DEUG & 0 & 4 & 26 & 30 \\
\hline Licence & 0 & 0 & 32 & 32 \\
\hline total & 0 & 4 & 58 & 62 \\
\hline
\end{tabular}

Nevertheless, communication breakdown is to an extent inevitable where instructions are in the students' L2. For example, teachers report problems when they presume the students know a key word in the instructions. This is not just a question of specialist language, where prior knowledge is expected for concepts explored during the course, but jargon words such as "alternate lines" and "indent" are not at all obvious to many students. To overcome this, native French teachers report writing complex instructions or key words in French to help their students avoid misunderstandings. Interestingly in this case, teachers report that students still misunderstand even translated instructions again, a problem no doubt familiar to many classroom teachers.

Another problem arises where the students understand each individual word, yet do not understand the underlying speech act or illocutionary force of the instructions. As one teacher recognised: "It's not that they don't read; they don't register what they should or shouldn't do." Students have knowledge of the code but not the communicative meaning. of course, in face-to-face teaching, this may not be such a problem as it is in distance learning because, as one teacher explained, "if I were a face-to-face teacher I would intuit 
it, I can see their faces, I can see their eyes wrenched up - you're not understanding what I'm doing. But in distance there's no way except by homework."

Regardless of the language used, where teachers are native L2 speakers, intercultural differences may also be a factor in communication breakdown. This is intimately linked with pragmatic errors, which Riley (1989: 234) defines simply as resulting from "imposing the social rules of one culture... in a situation where the social rules of another culture would be more appropriate." In the light of this, native and non-native language teachers alike perhaps need to address the problem not only of which language is appropriate, but also of which culture - French (as we are working within the French educational system) or Anglo-Saxon (as the target language is inevitably highly acculturated). An element of moderation would seem to be desirable as the arguments abound back and forth on this thorny issue, but whatever the outcome, it would appear reasonable for teachers to make their approach clear to students at the outset.

One final argument in favour of instructions in the target language: where cultures clash, some students tend to assume a mistake on the part of the teacher, and plough on regardless with their own approach. This reaction may become more likely if a native teacher writes materials in the students' L1; the situation may ironically be exacerbated if the English writer uses perfect French (cf. Riley 1988). The fact of writing instructions in English is a constant reminder to the students to be on their guard against preconceived ideas of what may have been required in previous situations.

\section{Responsibility for communication breakdown}

Given that the students are majoring in English, many teachers are reluctant to take the entire blame for communication breakdown - the students also have a responsibility to make their best effort to understand instructions sensibly. Without wishing to overstate teachers' cynicism, there seems to be a perceived manifestation of Murphy's Law - if anything can be misunderstood, a student somewhere will find a way. In this way, they claim that many instances of communication breakdown are student-generated. The students too (especially in the DEUG course) are generally quick to blame themselves for problems in understanding what is required. Comments include: "erreurs bêtes"; "étourderie"; "inattention"; "oublis"; "je suis allé trop vite"; "pas assez attentive"; "problème de relecture".

Many students are philosophical about this: ("l'erreur est humaine"; "tout le monde fait des erreurs"), some assume the teacher is always right ("je reconnais mes erreurs et les corrections des professeurs sont justifiées"), while a very few are rather more bitter ("les correcteurs sont à mettre en cause également").

of course, all communication involves two active parties, and both necessarily have to share the responsibility for any breakdown. As our interest here is in communication breakdown and its avoidance, we necessarily concentrate more on the negative aspects. These include comments such as: "manque d'explications"; "imprécisions"; "les exercices ne sont pas toujours très clairement expliqués". Indeed, Thorpe (1988: 73) finds that "unclear wording" is one of the major hurdles students face in distance assignments.

While there is an abundance of "good study guides" on the market (e.g., Northedge 1990), these tend to put the onus on the student. Examination skills as presented here typically focus on such general features as revision and advance practice, presentation and 
handwriting, note-taking and rough drafts, timing and careful reading of the question. These are all of course important, but comparatively little work has been carried out with the aim of encouraging teachers or examiners to eliminate possible communication breakdown - Yalden's (1987) Principles of Course Design for Language Teaching, for example, makes no explicit reference to such problems. Surprisingly, this also seems to be the case in other areas outlined at the beginning, such as self-access (e.g. Gardner \& Miller 1999) and materials design in general (e.g., Fenner \& Newby 2000).

To change the emphasis, we can adapt three of Grice's (1975) maxims of conversation:

The maxim of quantity: instructions should be as informative as required, no more

nor less.

The maxim of relation: instructions should be relevant.

The maxim of manner: instructions should be perspicuous - orderly and brief, avoiding obscurity and ambiguity.

Bearing these in mind, some of the onus for communication breakdown can be shifted back again from the student to the teacher. It is perhaps worth pointing out that the teacher's role is no less important in distance learning than in classroom learning (Desmarais 2000). This is supported by the finding that two thirds of distance students feel that "a good tutor can make a course, a poor tutor can spoil one" (Thorpe 1988: 69). In other words, communication depends on both parties, and it is not a solution simply to blame the students - or the teachers. On the one hand, it is clear that students do not pay sufficient attention to the instructions provided; on the other hand, there are a number of guidelines that teachers can follow in order to eliminate communication breakdown and improve performance. It is to this that we turn in the final sections.

\section{Writing courses}

We now proceed to examine a number of practical and theoretical considerations involved in writing courses in general, and instructions in particular. Some of the teachers we interviewed were surprisingly aware of the causes of communication breakdown at a distance and on-line. They were fairly unanimous in reporting that imprecise and ambiguous language leads to misunderstanding. Most teachers could recall instructions they had written which caused students' responses to be inappropriate or, worst of all, left students at a total loss as to what to do. Both natives and non-natives reported using a simpler - but not simplistic - structure and style to keep everything as transparent and complete as possible. For first-year courses, teachers reported making a conscious effort to avoid writing that was too dense, while in more advanced courses teachers were aware of grading their language less.

41 The teachers who participated in the interviews were fairly homogeneous in the way they approach course writing. All were aware of the need to write materials which followed a logical, simple structure. Some admit that this places a measure of restriction on what can be accomplished. Face-to-face teaching offers a certain amount of flexibility, insofar as a teacher can backtrack or offer a wider description where necessary, can jump from topic to topic, and can be less worried about accuracy. As one teacher highlighted, "there is no cutting or pasting when you are in front of a class." With online teaching, this flexibility is greatly reduced, as everything has to be planned in advance, and nothing can be improvised as in a normal classroom. 

"chatty" tone of voice when writing to reduce the distance with students and to make the materials more personal. One teacher neatly summarised it as placing his voice between an academic tone and a casual tone: the former would be too cold while the latter would cause a lack of respect. This was particularly true of the native English teachers, and can thus be attributed at least partly to cultural causes. For the non-natives, this sense of compensating for the distance manifested itself in another way. For them, there was a need to be more didactic, more educational. So they would translate difficult instructions into French, repeat instructions more, etc. However, it seems that a less formal style is appreciated by students, who use a very relaxed style on the CTU forum. This electronic medium has a double advantage in that students can contact each other and the teacher can post relevant messages for the students. It is particularly useful when a student asks a pertinent question in an e-mail to the teacher. The teacher can then post the information on the forum for the benefit of other students on the same course. At the time of writing, the majority of messages on the forum concerned pen friends, information about exam texts, and messages asking for (and providing) tips for certain courses.

Richards (1994) summarises a number of points which may help to improve accessibility of distance materials in general. These include the provision of clear objectives, concept maps and glossaries. Other helpful features include navigation devices, such as a contents page and an index, with the necessary titles, headings, and numbering; internal and external cross-referencing and signposts; helpful visuals and "user-friendly packaging" and the whole should be "relevant to learners' needs, attractively presented, written in a clear and friendly style, [and] designed to boost learners' confidence" (1994: 97). He also includes useful checklists of criteria the materials writer can bear in mind. These include relevance, redundancy, completeness, length, level, accuracy, clarity, coherence, variety, friendly tone, and balance between presentation and activity" (105). He also insists on the importance of multiple editing by several people before use.

While an explicit discussion of such features can only be beneficial, it seems that they are taken for granted by most teachers. Those we interviewed were also aware of and reported using various devices in the units to help guide the student through the course. Most commonly cited items included the use of page numbers, outlines, a contents page, references to materials used, typefaces to highlight emphasis, and clear structure.

\section{Writing instructions}

Such general guidelines stand us in good stead as we now turn in more detail to writing instructions for homework and exams, as much of this paper has focused explicitly on this. First of all, improvement is likely if the student knows in advance what to expect. External examinations such as TOEFL, TOEIC and UCLES rely on the same format for each examination session, highlighting the benefit of using similar exercise types repeatedly rather than varying each time. Past assignments with model answers can be made available for this purpose. Furthermore, students frequently complain about a "manque de pratique", and so should be made familiar with the question types and examiners' desiderata through repeated practice prior to important examinations. Indeed, this is one of the major reasons for providing homework in the courses at the CTU. As one student wrote, "[il faut] comprendre vraiment la manière de fonctionner et l'attente de l'enseignant." 

than relying on the students having prepared explicitly and remembering requirements from the course. Indeed, it seems that general guidelines presented some time prior to the exercise are likely to be forgotten, and need repeating each time. Excessive adherence to this policy may however lead to instructions that are too long and hence not read in sufficient detail; Richards (1994) suggests that half a dozen elements ought to be a maximum. One way round this is to use visual clues to highlight the most important considerations. These include typeface and font size, capitalisation, italics, underlining and bold type; on the Internet, additional use may be made of colour and animated graphics, not to mention interactive links. to test the student's knowledge and skills rather than their ability to interpret the question itself. To this end, similar vocabulary should be used throughout the course, and even across courses where possible. Simple language should be used in preference to technical jargon (e.g., cloze and gap-fill) to avoid comments such as "[le] vocabulaire utilisé [est] souvent inaccessible au commun des mortels." Sample questions and answers may be provided for many types of questions as a model.

Richards (1994: 99) points out that objectives in general should be:

unambiguous, jargon-free, concise. For the sake of precision:

- avoid vague terms (e.g. understand and appreciate the significance of describe states

which are hard to pin down and can't easily be checked);

- use verbs relating to specific actions wherever possible (e.g. state, list, show, give examples of);

- specify the conditions and standards of performance where appropriate (e.g. using your own notes, summarise... in around 500 words).

Information about the marking system also provides valuable information. A clear statement of the number of points available for each question provides an indication to the time the student should devote to each. Omission of questions may occur if the student suspects that poor answers will incur negative marks rather than zero. The examiner also needs to communicate a clear idea of what constitutes a formally unsatisfactory answer; for example, if a content question is answered in French rather than English, what penalty (if any) does this entail?

Where practical, a blank answer sheet also gives an indication of the type of response required, from a simple number or word to a sentence or longer description. This also makes clear any question where students have a choice among several items, and can eliminate accidental omission.

\section{Conclusions}

The title of this paper may have struck a somewhat pessimistic or cynical note, but the question remains - to what extent are we communicating into the void, and is communication avoided? We have seen that problems of communication are exacerbated in distance education by a lack of contact between students and teachers. When students do make contact, this is largely for pragmatic reasons and not, generally, on any other level. Moreover, this lack of contact between the participants limits their relationship, and thus has a vital part to play in undermining understanding on several levels. 

and achieve their learning goals, this is not always successful. We have seen that there are various tools which can aid the comprehension of materials, however it is rather more tricky to encourage greater participation and hence avoid communication breakdown. Until we fully understand the affective factors (how learners actually approach the learning task, process the language and understand the course requirements), all we can do is hypothesise.

We have also seen that the language itself may not necessarily be a barrier. However, it is worth considering that English and French are not only separate languages, but they also carry separate cultural messages which influence the learners. More encouraging is that as a greater number of our students come on-line, greater contact can be encouraged through e-mail or the forum; a non-threatening dialogue can thus take place which can help to minimise or prevent misunderstandings. As well as a quantitative shift in the volume of messages, we may also see a qualitative shift towards a deeper discussion and hence a more complete understanding of the course and the requirements.

\section{BIBLIOGRAPHY}

Desmarais, L. 2000. “La persévérance dans l'enseignement à distance. Une étude de cas”. ALSIC 3/1, 49-59.

Dubin, F. \& E. Olshtain. 1986. Course Design: Developing programs and materials for language learning. Cambridge: Cambridge University Press.

Dudeney, G. 2000. The Internet and the language classroom: a practical guide for teachers. Cambridge: Cambridge University Press.

Esch, E. 1994. "Learner support: interacting with learners". In Esch, E. (ed.), Self-access and the Adult Language Learner.London: CILT, 50-53.

Fenner, A-B. \& D. Newby. 2000. Approaches to Materials Design in European Textbooks: Implementing principles of authenticity, learner autonomy, cultural awareness. Council of Europe: European Centre for Modern Languages.

Gardner, D. \& L. Miller. 1999. Establishing Self Access: From theory to practice, Cambridge: Cambridge University Press.

Grice, P. 1975. "Logic and conversation”. In Cole P. \& J.L. Morgan (eds.), Syntax and Semantics. Volume III: Speech acts. New York: Academic Press, 51-58.

Makin, L. 1994. “Learner telesupport: language advising by e-mail”. In Esch, E. (ed.), Self-access and the Adult Language Learner. London: CILT, 83-96.

Northedge, A. 1990. The Good Study Guide. Milton Keynes: Open University.

Pincas, A. 1998. "The near and distant future of educational culture. New kinds of "book", porous knowledge domains, and new uses of language". Indian Journal of Open Learning 7/1, 129-142. 
Richards, K. 1994. “Writing distance learning materials”. In Richards K. and P. Roe (eds.), ELT and Distance Learning. London: Macmillan, 94-107.

Riley, P. 1988. "Who do you think you're talking to? Perception, categorisation and negotiation process in exolinguistic interation". In Bickley, V. (ed.), Languages in Education in a Bi-lingual or Multi-lingual Setting. Hong Kong: Institute of Language in Education, Hong Kong Education Dept., 118-133.

Riley, P. 1989. “Well don't blame me! On the interpretation of pragmatic errors”. In Oleksy, W. (ed. ), Contrastive Pragmatics. Philadelphia: John Benjamins, 231-249.

Ryan, R. 1992. "International connectivity: A survey of attitudes about cultural and national differences encountered in computer-mediated communication", Online Chronicle of Distance Education and Communication http://cyber.eserver.org/com_medi.txt.

Simpson, O. 2000. Supporting Students in Open and Distance Learning. London: Kogan Page.

Thorpe, M. 1988. Evaluating Open and Distance Learning. Essex: Longman.

Yalden, J. 1987. Principles of Course Design for Language Teaching, Cambridge: Cambridge University Press.

\section{NOTES}

1. When questioned as to their motivation for following a distance degree, the commonest reasons cited were a job (63.5\%), children (28.6\%), distance from the university $(23.8 \%)$, and following another course simultaneously (7.9\%).

2. It is interesting to note a discrepancy with the number of assignments actually submitted against the number claimed by the student sample. Only $8 \%$ of those who completed the questionnaire admitted to never submitting any homework for a course, while well over a third of students actually submitted none for two courses examined. This perhaps confirms bias in the population sample, if only more motivated students returned the questionnaire.

\section{ABSTRACTS}

More and more traditional courses are being supplemented with components posted on an inhouse web site. This particularly concerns language teaching, which is justifiably proud of a long history of pedagogical research compared to other disciplines. However, the skills involved in classroom teaching and those used through the medium of Internet teaching are often highly dissimilar, which can lead to a number of problems. We focus specifically on computer-mediated communication and the way misunderstandings can arise. What kind of mediation is possible between learner and teacher in the Internet void? What kind of general communication problems occur most frequently? And how can they be avoided? These are some of the questions we consider, with reference to an on-going survey of learner-teacher communication breakdowns in on-line courses at the Centre de Télé-enseignement - Université Nancy. 
De plus en plus de cours traditionnels sont complétés par un enseignement en ligne. Ceci concerne tout particulièrement l'enseignement des langues qui a une longue histoire de recherches en didactique. Toutefois, les techniques requises dans la salle de classe ne ressemblent guère à celles nécessitées par un enseignement à distance ; par conséquent, l'adoption des nouvelles technologies n'est pas sans risque. Cet article portera surtout sur la communication par Internet et sur les différentes causes des malentendus. Quelle médiation est possible entre l'apprenant et l'enseignant dans l'abîme de l'Internet ? Quels sont les problèmes de communication les plus fréquents? Et comment les éviter? Ce sont quelques-unes des questions auxquelles nous nous adressons, en nous référant à une étude sur les pannes de communication en cours au Centre de Télé-enseignement - Université Nancy 2.

\section{INDEX}

Mots-clés: conception de cours, enseignement à distance, enseignement Internet, panne communicative

Keywords: communication breakdown, course writing, e-learning, open and distance learning

\section{AUTHORS}

\section{ALEX BOULTON}

Alex Boulton est maître de conférences à l'Université Nancy 2. Il a soutenu sa thèse intitulée «Le lexique mental L2 : connexions et associations" en 1998 à l'Université Nancy 2. Ses recherches portent sur les aspects psychologiques de l'apprentissage du vocabulaire L2, le lexique mental d'un apprenant L2, et plus précisément la manière dont les lexiques de deux langues coexistent dans un seul esprit. alex.boulton@univ-nancy2.fr

\section{PAUL BOOTH}

Paul Booth est maître de langues à l'Université Nancy 2. Il a obtenu sa maîtrise (TESOL) à l'Université de Londres en 1999 et il prépare actuellement son mémoire de DEA. Ses centres d'intérêt portent sur les stratégies d'apprentissage des langues étrangères.

p.booth@kingston.ac.uk 